Revista NEP - Núcleo de Estudos Paranaenses, Curitiba, v.5, n.1, jun. 2019

\title{
CAPITAIS, TRAJETÓRIAS E MODERNIDADE EM CURITIBA: UM ESTUDO DE CASO SOBRE BRANCA DO NASCIMENTO MIRANDA
}

\author{
Luciana Podlasek $^{1}$
}

\begin{abstract}
Resumo: O contexto de modernização na passagem do século XIX para o século XX foi um período de intensas transformações em diversas partes do mundo. A capital paranaense viveu esse processo, com características peculiares, que remetiam à suas origens agrícolas e ligadas ao sistema colonial brasileiro, ao mesmo tempo em que se direcionava para um grande esforço civilizatório inspirado nos modelos vindos da Europa e Estados Unidos. A ambiguidade foi a marca dessa fase histórica em Curitiba, pois, ao mesmo tempo em que a inovação da urbe moderna era desenhada em certas regiões da cidade, as marcas da desigualdade, do atraso econômico e da opressão patriarcal eram muito fortes. Ser mulher nesse contexto significava conviver com a dualidade do avanço e da manutenção da ordem dominante. O estudo de caso de uma componente das elites, a educadora Maria Branca do Nascimento Miranda, revela traços interessantes da dinâmica da modernização curitibana, e da ocupação de espaços pelas mulheres daquela época.
\end{abstract}

Palavras-chave: Modernidade, mulheres, Branca do Nascimento, capitais, trajetórias.

\section{CAPITAL, TRAJECTORIES AND MODERNITY IN CURITIBA: A CASE STUDY ON WHITE OF BRANCA DO NASCIMENTO MIRANDA}

\begin{abstract}
The context of modernization in the passage from the nineteenth century to the twentieth century was a period of intense transformation in various parts of the world. The capital of Paraná lived this process, with peculiar characteristics, that refer to its agricultural origins and linked to the Brazilian colonial system, at the same time that it was directed towards a great civilizational effort inspired by the models coming from Europe and the United States. Ambiguity was the hallmark of this historic phase in Curitiba, for at the same time that the innovation of the modern city was drawn in certain regions of the city, the marks of inequality, economic backwardness and patriarchal oppression were very strong. Being a woman in this context meant living with the duality of advancement and maintenance of the dominant order. The case study of a component of the elites, educator Maria Branca do Nascimento Miranda, reveals interesting features of the dynamics of modernization in Curitiba, and the occupation of spaces by the women of that time.
\end{abstract}

Keywords: Modernity, women, Branca do Nascimento, capitals, trajectories.

\footnotetext{
${ }^{1}$ Mestranda em Sociologia pela UFPR. Graduada em História pela UFPR. Integrante do Núcleo de Estudos Paranaenses na mesma instituição. Bolsista da CAPES. E-mail: lucianabenario@gmail.com
} 
Revista NEP - Núcleo de Estudos Paranaenses, Curitiba, v.5, n.1, jun. 2019

ISSN: 2447-5548

\section{O fin de siècle}

A passagem do século XIX para o século XX foi um período marcante na história das sociedades ocidentais. A considerável transformação no sistema capitalista, pautada na industrialização, modernização e crença no progresso e na ciência atingiu, nessa época, regiões de todo o globo, desde os grandes núcleos urbanos de desenvolvimento industrial e cultural da Europa e dos Estados Unidos, até regiões consideradas periféricas, como algumas das cidades brasileiras.

Curitiba, apesar de contar nesse período com um modesto desenvolvimento urbano em comparação com outras metrópoles, e ainda carregar fortes traços da tradição econômica agrícola, foi uma cidade que também vivenciou o processo de modernização característico do início do século XX. Capital do estado do Paraná (emancipado de São Paulo somente em 1853), a cidade, assim como o restante da unidade da federação, carecia da estrutura administrativa, burocrática, educacional e econômica que a sustentasse. Por esse motivo, existiam todos os tipos de projetos sendo desenvolvidos para que Curitiba se tornasse verdadeiramente uma cidade adequada e digna de abrigar o governo do estado e suas personalidades ilustres (CASTRO, 2018).

As mudanças e novas ideias que a modernidade da virada do século trouxe para Curitiba, guardadas as especificidades históricas, afetaram não somente a aparência e a estrutura física da cidade, mas também tiveram impacto na construção da mentalidade e no cotidiano dos indivíduos. Para analisar tal dinâmica, as ferramentas que ciências como a História e a Sociologia nos fornecem são bastante pertinentes. Quando afirma que a Sociologia é uma narrativa da modernidade, Rita Felski (1995) situa o período da passagem do século XIX para o século XX como uma época privilegiada para a análise dessa fase do mundo capitalista, sobretudo no estudo das relações de gênero e do movimento feminista, sempre tendo em mente que se trata de um contexto multifacetado, que muitas vezes carrega ambiguidades e contradições.

(...) the idea of the modern saturates the discourses, images, and narratives of the late nineteenth and early twentieth centuries. It is an era profoundly shaped by logics of periodization, by the attempt to situate individual lives and experiences in relation to broader historical patterns andoverarching narratives of innovation and decline. "Modernity" thus refers not simply to a 
Revista NEP - Núcleo de Estudos Paranaenses, Curitiba, v.5, n.1, jun. 2019

substantive range of sociohistorical phenomena-capitalism, bureaucracy, technological development, and so on-but above all to particular (though often contradictory) experiences of temporality and historical consciousness. (FELSKI, 1995, p. 09.). ${ }^{2}$

Nesse sentido, observar alguns traços desse processo de mudança dentro das especificidades e da historicidade de uma comunidade local, e analisar sua correlação com a ocupação ou reordenação do espaço feminino, a partir de um estudo de caso, é a proposta do presente trabalho. A trajetória da professora Branca do Nascimento Miranda (personalidade feminina reconhecida na capital, tendo seu nome como homenageada em uma rua e um estabelecimento escolar da cidade) coincide com os primeiros anos do século XX, época da modernização curitibana. Em que medida a história dessa professora pode nos revelar aspectos das sociabilidades em relação ao mundo feminino, e as conexões com suas origens familiares e de classe são o foco da presente análise.

\section{Curitiba, a mulher e a modernidade}

A implantação do regime republicano em 1889 acelerou o processo de urbanização que Curitiba vivenciava desde a emancipação política do Paraná em 1853. Capital do estado, a cidade atravessava um período de intensa remodelação para atender aos padrões de uma sede administrativa condizente com os ideais de ordem e progresso que eram prerrogativas do novo regime.

O governo aprimora os serviços: higieniza o centro urbano com irrigação, limpeza pública, água e esgotos; implementa a arborização e instala iluminação pública; cria, inclusive uma guarda civil.

A cidade diversifica, ainda, espaços públicos com cafés e salas de espetáculos; parques e praças - suas novas opções em áreas de lazer. Nas ruas principais agências bancárias e casas comerciais abrem suas portas (...). Nessa nova Curitiba, vai-se também encontrar os representantes de um ativo círculo literário (...) É um grupo que circula não apenas nos salões de clubes elegantes, como em inúmeros grêmios, associações e congregações. São eles que dão ao universo pensante da cidade um toque de paixão, ação, sonhos medos e esperanças, ideias e práticas. Sua vigorosa

2 “(...) a ideia do moderno satura os discursos, as imagens, e as narrativas do final do século XIX e início do século XX. Trata-se de uma era profundamente moldada pela lógica da periodização, pela tentativa de situar a vida e a experiência individuais em relação a padrões históricos mais amplos e a narrativas abrangentes de inovação e declínio. 'Modernidade' assim se refere não simplesmente a um conjunto substancial de fenômenos sociais capitalismo, burocracia, desenvolvimento tecnológico, entre outros - mas acima de tudo a experiências específicas (apesar de frequentemente contraditórias) de temporalidade e de consciência histórica" (PUPPO, 2013, [s/p]). 
Revista NEP - Núcleo de Estudos Paranaenses, Curitiba, v.5, n.1, jun. 2019 Dossiê Partidos Políticos e Conexões Familiares

ISSN: 2447-5548

produção literária gera um sem-número de livros, revistas e jornais. (TRINDADE, 1996, p. 20)

Ao mesmo tempo em que se modernizava, Curitiba tentava manter características próprias, procurando se afastar da imagem de outros centros urbanos brasileiros, como São Paulo e Rio de Janeiro. Era a construção de um imaginário social próprio, curitibano, onde a figura de um povo morigerado e civilizado, mesclado ao componente imigrante e às características civilizatórias inspiradas no padrão europeu se sedimentava. Curitiba podia não ser a mais dinâmica ou mais industrializada capital da República, mas pretendia ser a mais civilizada, a mais avançada cultural e intelectualmente e a mais desenvolvida em termos de organização e planejamento urbano. É claro que esse tipo de construção imagética escamoteia os problemas sociais que toda cidade enfrenta. A prostituição, a vadiagem e a mendicância, por exemplo, eram problemas reais na Curitiba do início do século XX. Contudo, aqui existia um forte apelo para que essa parcela da realidade social fosse, em certa medida, ocultada pela imagem da cidade moderna e avançada.

\footnotetext{
A vontade de civilizar a "urbs" marca o final do século XIX e o início do século XX em Curitiba. As políticas públicas implantadas pelos prefeitos cujos mandatos atravessaram esse período - como o Código de Posturas Municipais, leis e medidas políticas - estiveram imbuídas deste ideal, buscando caracterizar a cidade como civilizada e moderna. Sempre que possível estabeleciam-se diferenças em relação aos outros centros urbanos nacionais (...), a fim de qualificar a "pequena urbs" como "terra do futuro".

(...)

Com "intensa e expressiva atividade social", era exaltada a superior distinção do gosto dos curitibanos na arte, na indumentária e nos "espíritos incorruptíveis" de seus artistas e homens de letras, considerados formadores de opinião (...). Às mulheres curitibanas acrescentava-se a qualidade de comunicativas e acolhedoras, além de "chics" e "bem postas" de corpo e alma. (CUNHA, 2001, p. 22-23).
}

Mas qual seria o papel e o espaço da mulher na Curitiba que se modernizava? De forma geral, o novo espaço urbano da modernidade (na capital paranaense, ou nos grandes centros da Europa) produz impressões que são marcadamente masculinas. A família, a política, o espaço público, a igreja, eram ainda territórios de expressão da dominação patriarcal. Contudo, essa dominação é um dos aspectos (talvez mais evidente e expressivo) da trama social, mas não abarca sua totalidade. Em outras palavras, a presença feminina, e suas formas de inserção e luta por voz e representatividade, assim como o papel e o comportamento dos homens nessa dinâmica devem ser observados na complexidade das relações sociais e de gênero. 
Revista NEP - Núcleo de Estudos Paranaenses, Curitiba, v.5, n.1, jun. 2019

O sociólogo alemão Georg Simmel (1858-1918) aponta para uma noção diferenciada a respeito dessas relações de gênero, numa postura bastante dissonante do que se produzia em boa parte do meio intelectual e acadêmico da segunda metade do século XIX. Para ele, o homem encarnaria a objetividade e a fragmentação do mundo moderno e industrial, enquanto a mulher seria a subjetividade e a unicidade perdida na sociedade capitalista. Longe de criticar essa "essência subjetiva" feminina, que era parte do imaginário social e intelectual, Simmel enxergava nela uma virtude e uma possibilidade de encarar a modernidade de maneira menos fragmentada e mais sensível (FELSKI, 1995).

Tal perspectiva de Simmel hoje é criticada por sujeitar a diferença entre homens e mulheres à "essência de cada sexo" (CUNHA, 2001), colocando em segundo plano, ou mesmo não considerando as questões estruturais e culturais desse processo. De qualquer maneira, quando elabora seu pensamento, Simmel aponta para a importância dos estudos dos movimentos das mulheres e para a própria natureza do que é ser feminina naquela sociedade. Em outras palavras, quando Simmel fala da sensibilidade feminina, ele também remete à necessidade de se pensar a mulher fora do universo ao qual ela normalmente é submetida, ou seja, o universo exclusivo da lógica masculina. Observar a mulher pelas suas singularidades (apesar das noções de nostalgia que essa análise carrega) faz da perspectiva de Simmel uma possibilidade de pensar as mulheres a partir delas mesmas, especialmente na modernidade, época classificada como racional, fragmentada e masculina por excelência (FELSKI, 1995).

Se Simmel aponta para a possibilidade de análise do universo feminino por meio de uma ótica própria, a ideia de que a modernidade tem um gênero, que é a priori masculino, pode também ser questionada. Mesmo que na academia, nos círculos intelectuais e culturais e no universo popular, a dominação dos valores patriarcais predomine na maioria das sociedades da virada do século, uma observação mais atenta e diversificada desse período pode apontar para a existência de um universo de estratégias, que faziam da modernidade uma época com brechas para que grupos, a princípio invisibilizados, se fizessem presentes das mais diferentes formas (FELSKI, 1995).

Na Curitiba do início do século XX, as relações existentes nos círculos de poder, nas instituições religiosas, no universo cultural, na realidade educacional e nas demais esferas das sociabilidades revelavam um ambiente propício para certa inserção, ainda que periférica, de 
alguns grupos marginalizados ${ }^{3}$, mesmo que, de forma geral, se conservasse a maioria dos mecanismos de dominação. Nesse contexto, as relações de gênero também sofreram algumas transformações perceptíveis. Exemplo disso está no fato das mulheres, antes circunscritas apenas ao recinto privado dos lares, passarem a frequentar alguns espaços públicos, como as novas lojas que se espalhavam pela região central da Praça Tiradentes, os cinematógrafos ${ }^{4}$ que proliferaram pela cidade, as feiras de comércio da produção agrícola das colônias imigrantes (onde eram as colonas que negociavam as mercadorias), ou a ocupação do espaço educacional, onde as mulheres se faziam presentes em maior número, como alunas ou professoras em escolas públicas e particulares.

A cidade se modernizava e as fronteiras entre os sexos se movimentavam, ora rompendo, ora reafirmando valores tradicionais numa engenhosa mescla de mudança e manutenção de costumes tradicionais. Modernização, progresso, civilização! Temas diários nesse "fin-de-siècle". A explosão de novidades modernas vinha junto com a aclamação dos padrões europeus de civilidade, despertando nos curitibanos um sentimento de profunda transformação. (CUNHA, 2001, p. 21).

Em meio a esse processo, vale ressaltar o papel de destaque atribuído à educação escolar. Imbuídos da mentalidade republicana, moderna e laica, os poderes públicos e os entusiastas da modernização da capital defendiam a necessidade de um projeto de organização escolar para garantir o desenvolvimento civilizado da urbe. Ainda que a realidade concreta estivesse muito aquém do que se exigia para a real inclusão escolar da maioria dos cidadãos, a educação certamente era foco central dos discursos modernizantes.

As mulheres das elites ou das classes populares que tinham a oportunidade de frequentar os bancos escolares enfrentavam as limitações impostas pela dominação patriarcal da época. Se

\footnotetext{
${ }^{3}$ Em Curitiba e no Paraná como um todo, além das lutas feministas, a atuação de outros grupos por visibilidade e cidadania é significativa nesse período da virada do século e também posteriormente. A coletânea de artigos presentes na obra "Paraná insurgente: história e lutas sociais - séculos XVIII ao XXI" (MENDONÇA; SOUZA, 2018) relata diversos exemplos dessas lutas, que englobavam os movimentos abolicionistas e pó-abolição, de luta dos trabalhadores rurais pela terra, e os enfrentamentos dos trabalhadores urbanos por voz e direitos.

${ }^{4}$ Um caso interessante é descrito por Renata Cunha (2001) em sua dissertação de mestrado, quando a autora relata o caso do conflito das senhoras elegantes de Curitiba com o público masculino em geral, devido ao hábito delas de comparecer aos cinemas com chapéus da última moda, que eram grandes e vistosos, e atrapalhavam muitas vezes a visão dos que frequentavam o recinto. Mesmo com muitas críticas e sátiras na imprensa, por algum tempo as mulheres se recusaram a abrir mão de seus adornos, marcando posição diante da chacota masculina (CUNHA, 2001). No livro "El consumo de la utopia romântica", Eva Illouz chama a atenção justamente para como o consumo e a moda, a partir do século XX, se transformaram em instrumentos que possibilitaram, entre outras coisas, maior poder de escolha e visibilidade para as mulheres (ILLOUZ, 2009).
} 
oriundas das elites, eram formadas para as prendas domésticas, para o cuidado familiar, para o desenvolvimento do bom comportamento social, aprendendo rudimentos das ciências, da música e da literatura que garantissem o traquejo necessário à um dama da sociedade. Quando originárias das classes populares, além das prendas domésticas, as meninas também aprendiam ofícios como corte e costura, bordado, ou outras formas de atuação profissional que lhes garantisse a renda necessária à sua condição social. O ensino aprofundado das ciências naturais, da matemática, da sociologia ou da política era considerado desnecessário, uma vez que se tratava de áreas racionais e, consequentemente, de domínio masculino (TRINDADE, 1996). Contudo, mesmo com todas essas limitações, o fato de mulheres adentrarem ao universo educacional em maior número, demonstra as mudanças de concepção sobre a educação feminina, e suscita a possibilidade da existência de novas formas de relacionamento dessas mulheres com o conhecimento que lhes era oportunizado.

A partir do final do século XIX e início do século XX, esse processo de maior inserção das mulheres no universo educacional paranaense se tornou evidente, e refletiu uma crescente ocupação feminina nos postos do magistério. A criação da Escola Normal em Curitiba (1876) e o aumento da entrada de mulheres nos quadros docentes do estado revelam um projeto de transformação do quadro funcional do magistério, que passou a ser essencialmente feminino, especialmente nas décadas posteriores do século XX. Tal processo histórico se explica, em certa medida, pelas transformações econômicas do período, quando profissões ligadas à produção industrial e ao aparato estatal se mostravam mais atraentes e mais bem remuneradas, despertando o interesse dos contingentes masculinos que se formavam e buscavam colocação no mercado de trabalho. Os baixos salários e a falta de prestígio que eram característicos da carreira do magistério provocaram nesse período o abandono paulatino do ofício de professor pelos homens, que se deslocaram para outras profissões, ou passaram a ocupar privilegiadamente os cargos de direção das instituições de ensino ${ }^{5}$.

Em consonância com o processo de feminização do magistério, desenvolveu-se todo um discurso sobre a vocação das mulheres para tal ofício, uma vez que o trabalho da professora

\footnotetext{
${ }^{5}$ Exemplo desse processo de exclusão das mulheres dos cargos de direção nas instituições de ensino do Paraná pode ser observado no histórico da antiga Escola Normal de Curitiba. Além de a referida instituição carregar hoje um nome masculino como homenageado - Instituto de Educação do Paraná Professor Erasmo Pilotto - dos trinta e cinco diretores que ocuparam o cargo entre 1876 e 1982, apenas cinco foram mulheres. (VIANA, 2011, p. 2310).
} 
envolvia a dedicação e o amor maternal para cuidar da própria família, e dos filhos de outras famílias.

\begin{abstract}
(...), este discurso [da vocação feminina para a docência] foi também fator de abandono do exercício do magistério pelos homens, por estar relacionado à representação da capacidade natural da mulher para a maternidade e educação dos filhos (...). Entretanto, mesmo com a redução dos homens no magistério (...), aqueles que continuaram na carreira ocuparam frequentemente as funções mais valorizadas e melhor pagas como as de direção e de inspeção escolar. (VIANA, 2011, p. 2309).
\end{abstract}

Portanto, mesmo que o acesso à formação escolar e à ocupação de postos de trabalho no magistério tenha garantido maior inserção, voz e representatividade para as mulheres na Curitiba que se modernizava no início do século XX, este foi um processo ainda pautado pela lógica masculina, que fez da profissão de professora um modelo de representação do feminino disciplinado, extensão da esposa e da mãe submissa, e sem grandes ambições profissionais. Mesmo assim, essa não deixava de ser uma brecha para que as mulheres, antes totalmente restritas ao espaço doméstico, pudessem ter acesso à formação escolar e a uma ocupação profissional, mesmo que esta fosse desvalorizada aos olhos da sociedade.

O caso da professora Branca do Nascimento Miranda caracteriza certos aspectos desta realidade. Originária de famílias da classe média e da elite, a educadora se formou na Escola Normal de Curitiba aos 17 anos e, aos 20 anos, se casou com o empresário Guilherme Xavier de Miranda, que a proibiu de exercer o ofício do magistério fora de casa. Mesmo assim, Dona Branca, como era conhecida, passou a exercer a docência alguns anos mais tarde, em sua residência, ministrando aulas particulares para parentes e pessoas próximas. Como era de se esperar de uma mulher de sua origem e posição social, Branca do Nascimento Miranda nunca deixou de desempenhar o papel que lhe era atribuído de boa esposa e mãe dedicada, sendo o seu casamento mencionado pela imprensa da época como um exemplo a ser seguido e invejado na sociedade curitibana.

Bodas de Prata

A data de hoje marca o alegre transcurso do feliz $25^{\circ}$ aniversário de matrimônio do Sr. Guilherme Xavier de Miranda e sua Exma. esposa D. Branca do Nascimento Miranda. O distinto casal, que na sociedade curitibana desfruta um lugar de invejável destaque, constituindo um dos ramos de duas das mais destacadas famílias paranaenses deverá receber pela passagem de tão alegre quão significativa data as maiores demonstrações de apreço e júbilo de todos os que contam no número de suas relações (CORREIO DO PARANÁ, 16 de julho de 1937, p. 9.). 
Revista NEP - Núcleo de Estudos Paranaenses, Curitiba, v.5, n.1, jun. 2019 Dossiê Partidos Políticos e Conexões Familiares

ISSN: 2447-5548

Compreender a trajetória de Branca do Nascimento Miranda dentro do contexto de modernização curitibana implica em enxergá-la como uma pessoa de seu tempo, que vivenciou as ambiguidades e tensões de uma época de mudanças. Isso significa que a postura de Dona Branca, especialmente na sua atuação no magistério, não apontam para um desafio da lógica opressora masculina, mas sugerem a utilização de estratégias de convencimento e conciliação, num processo de conquistas de espaços gradativas e socialmente aceitas pela estrutura patriarcal que imperava entre as elites ${ }^{6}$.

Por fim, a análise da história de Dona Branca na sociedade curitibana, também requer o estudo das suas origens familiares, sociais e de classe. $\mathrm{O}$ fato de ser originária de famílias pertencentes a círculos da classe média e da elite, de poder se instruir quando isso era considerado um privilégio para a maioria da população brasileira, de ter um casamento nos moldes tradicionais e dentro de seu meio social são aspectos de uma trajetória que revela um acúmulo de capitais importantes para sua aceitação e reconhecimento na sociedade a qual pertencia. Por isso, o conceito de capitais de Pierre Bourdieu (2012) também é bastante pertinente. A educadora, reconhecida pelas homenagens que lhes foram prestadas, foi uma mulher que, por sua origem familiar e de classe, já dispunha de recursos favoráveis que lhe permitiram uma formação qualificada, o exercício de uma profissão (ainda que fora do espaço público), e o reconhecimento de seus méritos nos meios sociais mais importantes da comunidade. Por outro lado, a história de vida de Branca do Nascimento de Miranda também revela aspectos de conformação e adaptação ao modelo de dominação de sua época. Por isso, os conceitos de habitus e dominação simbólica, também presentes em análises de Bourdieu, são bastante úteis, no sentido de compreender como as práticas de dominação se perpetuam de forma quase que naturalizadas, fazendo com que grupos sociais inteiros se comportem de maneira a reproduzir as estruturas de dominação tendo, inclusive, entre os próprios dominados um conjunto de atitudes e comportamentos que justificam e reforçam o sistema opressor (BOURDIEU, 2012).

\footnotetext{
${ }^{6} \mathrm{~A}$ forma com que as mulheres se fizeram presentes na modernidade curitibana também revela histórias diferentes daquela aqui analisada sobre a educadora Branca do Nascimento Miranda. Professoras e intelectuais como Mariana Coelho (1857-1880) e Júlia Wanderley (1874-1918) manifestavam em seus discursos, questionamentos mais contundentes a respeito de certos valores patriarcais, o que as levou a romper com alguns padrões estabelecidos, principalmente marcando posição em espaços que eram de domínio masculino, em especial entre a intelectualidade local (F0GGIATO, 2017, [s/p]) (ARAÚJO, [s/d], p.1-14).
} 
Revista NEP - Núcleo de Estudos Paranaenses, Curitiba, v.5, n.1, jun. 2019

\section{Maria Branca Garcez do Nascimento Miranda}

Filha de Francisco Gonçalves do Nascimento Rosa e de Olympia Garcez do Nascimento, Maria Branca Garcez do Nascimento nasceu em 16 de julho de 1892, em Curitiba. Originária de famílias de posses (militares e funcionários públicos), a jovem Maria Branca experimentou uma vida confortável na infância, e teve acesso à formação escolar, o que era ainda privilégio para a maioria das jovens brasileiras. ${ }^{7}$

A documentação levantada acerca dos primeiros anos de instrução escolar de Maria Branca do Nascimento faz referência à sua presença no Conservatório de Belas Artes de Curitiba, onde concluiu seus exames nas disciplinas de Gramática Musical, Português, Aritmética e Geometria, no ano de $1902^{8}$.

No ano de1903, Branca do Nascimento frequentou as aulas para a conclusão da $8^{\mathrm{a}}$ cadeira (ensino primário), num grupo organizado por sua irmã, a Professora Maria Rosa do Nascimento Bittencourt. Tratava-se de uma turma "promíscua" (denominação escolar utilizada na época para as turmas mistas, ou seja, frequentada por meninos e meninas) que, concluída a fase de aprendizagem anual, prestou exames para aprovação no final daquele ano. A aluna foi plenamente aprovada, com o interessante detalhe que D. Elfrida do Nascimento, outra irmã de Branca do Nascimento, fazia parte da banca examinadora ${ }^{9}$.

Após frequentar as aulas na turma em que sua irmã, Maria Rosa do Nascimento Bittencourt era professora, Branca do Nascimento deu prosseguimento à sua formação na Escola Oliveira Bello ${ }^{10}$, em Curitiba. Essa instituição escolar foi inaugurada em 28 de setembro de 1884 , e se enquadrava nos projetos de modernização da capital, sendo o nome uma homenagem ao Presidente da Província responsável por sua criação. (CASTRO, 2018).

A formação de Branca do Nascimento para a carreira no magistério se deu na Escola Normal de Curitiba, entre os anos de 1906 e 1909. Como na época, os investimentos em

\footnotetext{
${ }^{7}$ Para informações completas sobre os capitais familiares, educacionais, profissionais e sociais presentes na trajetória de Branca do Nascimento Miranda, ver o Anexo 01.

${ }^{8}$ Era costume na época publicar os resultados desse tipo de avaliação em certas seções de jornais, onde a presença de personalidades ilustres do meio educacional e intelectual sinalizava para os capitais sociais e culturais que aquele grupo possuía. É o caso dos exames prestados por Branca do Nascimento em 1902, quando o Secretário do Interior Octávio Ferreira do Amaral (1869-1942), e o renomado Inspetor Escolar, jornalista e deputado estadual Sebastião Paraná (1864-1938) fizeram parte do grupo de avaliadores (A REPÚBLICA, 9 de dezembro de 1902, p. 2) (A REPÚBLICA, 11 de dezembro de 1902, p. 1).

${ }^{9}$ A REPÚBLICA, 19 de novembro de 1903, p. 1.

${ }^{10}$ A REPÚBLICA, 3 de março de 1904, p. 2.
} 
Revista NEP - Núcleo de Estudos Paranaenses, Curitiba, v.5, n.1, jun. 2019

educação eram reduzidos por parte do poder governamental, a Escola Normal era obrigada a dividir seu espaço e corpo docente com o Ginásio Paranaense (instituição que oferecia cursos de caráter propedêutico $)^{11}$. Isso demonstra que, mesmo com o forte discurso de modernização da capital, os reais investimentos na estrutura educacional ainda eram falhos, mesmo que as instituições escolares atendessem membros oriundos das famílias mais ricas.

Em janeiro de 1909, Branca do Nascimento concluiu seus últimos exames para a formação na Escola Normal ${ }^{12}$ e, em dezembro do mesmo ano, ela já atuava como avaliadora em exames da Escola Americana, instituição particular da capital ${ }^{13}$.

Em 1912, Branca do Nascimento se casou com o empresário Guilherme Xavier de Miranda, passando a dedicar-se, a partir de então ao casamento, ao lar e aos quatro filhos: Guilherme Xavier de Miranda Jr, Carlos Xavier de Miranda, Maria da Anunciação Miranda e Lia Xavier de Miranda. Entre 1912 e 1920, não foram encontradas fontes referentes à atuação de Dona Branca na carreira do magistério. Por outro lado, sua presença é mencionada em festividades promovidas por paróquias católicas, e em eventos sociais da elite curitibana ${ }^{14}$.

Segundo informações que constam da biografia da professora no acervo do Colégio Estadual que leva seu nome em Curitiba, durante o final da década de 1920, a educadora retornou para o ofício do magistério, iniciando um trabalho de ensino das primeiras letras junto a seus sobrinhos. A experiência foi exitosa, e logo surgiram pedidos de outros parentes e conhecidos para que a professora aumentasse o número de vagas em sua casa, começando assim um ofício de ensino particular em sua própria residência. Não foram encontrados ainda registros sobre a forma com que essa iniciativa se concretizou dentro dos parâmetros legais da época em Curitiba, mas a mesma fonte citada anteriormente afirma que as salas de aula de Dona Branca permaneceram ativas por 25 anos em sua residência na capital (COLÉGIO ESTADUAL DONA BRANCA DE NASCIMENTO MIRANDA, [s/d]).

Mesmo com os bons resultados de seu trabalho como educadora, Dona Branca nunca teve permissão do marido para exercer sua profissão fora do espaço do lar. Durante o governo de Caetano Munhoz da Rocha ${ }^{15}$, a professora teria recebido o convite para assumir o cargo de

\footnotetext{
${ }^{11}$ A Escola Normal de Curitiba funcionou de 1876 até 1923 no mesmo espaço do antigo Ginásio Paranaense (IEP, $[\mathrm{s} / \mathrm{d}])$.

12 O COMMERCIO, 21 de janeiro de 1909, p. 2.

13 A REPÚBLICA. 02 de dezembro de 1909, p. 2.

${ }^{14}$ A REPÚBLICA, 5 de dezembro de 1917, p. 8.

O DIA, 02 de dezembro de 1944, p. 2.

15 Caetano Munhoz da Rocha (1879-1944), filho de Bento Munhoz da Rocha e Leocádia Munhoz Carneiro, formou-se em medicina em 1902, foi deputado estadual no Paraná entre 1904 e 1917, época em que também foi
} 
diretora da Escola Normal de Curitiba, mas o recusou, pois isso implicaria no seu afastamento dos deveres de mãe e esposa (COLÉGIO ESTADUAL DONA BRANCA DE NASCIMENTO MIRANDA, [s/d]). Tal recusa, pautada nas alegadas proibições do marido, certamente carregava componentes da lógica disciplinadora e cerceadora masculina diante das iniciativas de emancipação profissional feminina da época, especialmente entre as elites. Em nenhuma fonte, contudo, pode-se encontrar a própria fala de Dona Branca sobre essa situação, o que limita a análise sobre o posicionamento da educadora naquele contexto.

De qualquer maneira, o relato existente sobre a "proibição" do marido para que Dona Branca atuasse como professora fora do recinto do lar revela uma característica do habitus presente em tal época e grupo social. Trabalhar fora de casa era uma necessidade das mulheres pertencentes aos meios populares. As senhoras que faziam parte do círculo das elites não tinham essa necessidade material e, portanto, a proibição do marido poderia soar mais como "cuidado" ou "direito" do esposo sobre sua cônjuge, do que como uma prática de opressão e dominação. Dessa forma, a atitude proibitiva e cerceadora podia ser encarada de maneira natural, sem grande questionamento no meio social, ou mesmo entre as mulheres e jovens que viviam tal situação. O fato de Dona Branca encontrar uma alternativa para continuar exercendo o magistério, sem desafiar as imposições do marido, aponta nessa direção, e nos fornece indícios da presença de mecanismos de dominação simbólica.

\footnotetext{
Não se pode, portanto, pensar esta forma particular de dominação senão ultrapassando a alternativa da pressão (pelas forças) e do consentimento (às razões), da coerção mecânica e da submissão voluntária, livre, deliberada, ou até mesmo calculada. O efeito da dominação simbólica (seja ela de etnia, de gênero, de cultura, de língua etc.) se exerce não na lógica pura das consciências cognoscentes, mas através dos esquemas de percepção, de avaliação e de ação que são constitutivos dos habitus e que fundamentam, aquém das decisões da consciência e dos controles da vontade, uma relação de conhecimento profundamente obscura a ela mesma. Assim, a lógica paradoxal da dominação masculina e da submissão feminina, que se pode dizer ser, ao mesmo tempo e sem contradição, espontânea e extorquida, só pode ser compreendida se nos mantivermos atentos aos efeitos duradouros que a ordem social exerce sobre as mulheres (e os homens), ou seja, às disposições espontaneamente harmonizadas com esta ordem que as impõe. (BOURDIEU, 2012, p.50).
}

Uma matéria de jornal datada do ano de 1957, descrevendo aspectos da vida e dos pensamentos de Lia Xavier de Miranda Bley, uma das filhas de Branca do Nascimento, fornece algumas informações interessantes acerca do tema da emancipação profissional feminina, para

prefeito de Paranaguá, pois a legislação permitia o acúmulo de cargos. Foi vice-presidente do estado entre 1916 e 1920, e governador do estado por dois mandatos - 1920-24 e 1924-28. Casou-se por três vezes e teve 21 filhos. (GOVERNO DO PARANÁ, [s/d], [s/p]). 
uma geração posterior à de Dona Branca, no contexto do início da segunda metade do século XX:

\begin{abstract}
Sra. Evilazio Bley
Nascida Lia Xavier de Miranda, tem a Sra. Evilazio Bley desempenhado destacado papel em nossa vida social, principalmente por sua participação em obras assistenciais. Atualmente ocupa a função de secretária da Liga das Senhoras Católicas, dividindo assim o seu tempo entre as obras de caridade e o lar. (...) - "Acredito que os filhos e o lar exigem muito da mulher"- disse-nos quando lhe perguntamos como encarava a participação da mulher na sociedade. A Sra. Evilazio Bley é natural de Curitiba (...). Cursou a Escola Normal de Curitiba, diplomando-se professora e exercendo efetivamente a função até seu casamento, em 1948 com o Sr. Evilázio Bley, em cerimônia realizada na Igreja de Santa Terezinha. De vigorosa formação moral, a Sra. Evilazio Bley é antidivorcista por convicção e católica praticante.

(...) "Não creio que a mulher casada possa se dedicar às profissões liberais" respondeu a outra pergunta do cronista. "Entretanto admito que as solteiras possam ter êxito neste setor, já que a ele podem dedicar tempo integral" (DIÁRIO DO PARANÁ, 31 de março de 1957, p. 3).
\end{abstract}

É certo que não se pode tomar as falas de Lia Xavier de Miranda Bley como uma reprodução dos pensamentos de sua mãe. Contudo, é interessante notar que, apesar do posicionamento marcadamente conservador da filha da educadora, ainda assim em sua trajetória, ela teve acesso à formação escolar, exerceu o magistério quando solteira, e reconhece a possibilidade da atividade profissional para as mulheres não casadas. Para os dias de hoje, esse tipo de postura pode soar retrógrada e opressora em alguns meios. Porém, no contexto em que a filha de Dona Branca do Nascimento Miranda foi criada, e a partir de suas origens sociais, culturais e de classe, a mentalidade da esposa que se apresenta por meio do nome do marido ("Sra. Evilazio Bley”) talvez possa ser compreendida na dinâmica de modernização que Curitiba viveu durante o século XX, quando as transformações de inserção feminina em novos círculos de sociabilidades e representatividade conviviam com a imposição dos valores conservadores e opressores da lógica masculina patriarcal.

A outra filha de D. Branca do Nascimento Miranda, Maria da Anunciação Miranda, seguiu uma trajetória um pouco diferente da irmã. Formada no curso de Odontologia, exerceu sua profissão dentro dos quadros do funcionalismo público paranaense ${ }^{16}$, falecendo no dia 09 de novembro de 2010. Apesar de não serem encontradas fontes que demonstrem o posicionamento de Maria da Anunciação Miranda sobre o papel da mulher e das relações de

\footnotetext{
${ }^{16}$ Em 1962, Maria da Anunciação Miranda foi incluída no quadro provisório do funcionalismo estatal paranaense (DIÁRIO DO PARANÁ, 12 de julho de 1962, p. 1); em 2010 ela faleceu, constando de seu obituário a profissão "dentista" (PERES, 2010, [s/p]). Não foram encontrados registros sobre seu estado civil.
} 
gênero na sociedade curitibana, as informações acerca de sua vida revelam uma formação acadêmica completa, e uma atuação profissional contínua, o que destoava da trajetória de esposa e mãe que eram impostas para a maioria das mulheres do seu tempo e classe social.

Diante das informações levantadas sobre a vida das filhas de Dona Branca do Nascimento Miranda, é possível inferir que a educação tinha importância no lar dos Xavier de Miranda, tanto na formação dos filhos homens como das filhas mulheres, numa dinâmica que certamente era influenciada pela atuação de Dona Branca. Isso, contudo, não aponta para a existência de drásticas rupturas, nem processos traumáticos no seio doméstico, mas sim para uma possível inserção paulatina e discreta de novos valores e práticas acerca das relações de gênero, que podiam ser aceitos naquele contexto social. Mesmo assim, a ausência de fontes sobre os pensamentos da própria Dona Branca a respeito do tema da modernização curitibana que ela vivenciou, e das consequências desse processo, em especial sobre o papel e a representatividade feminina na sociedade, ainda é um fator que reduz as possibilidades de análise na pesquisa.

Maria Branca Garcez Xavier de Miranda faleceu em 27 de dezembro de 1954. No ano de 1959, foi inaugurada a Casa Escolar da Vila São Pedro, no atual bairro Tinguí em Curitiba. Em 1962, essa instituição escolar passou a se chamar Escola da Vila São Pedro e, em 1969, a denominação foi alterada para Grupo Escolar Dona Branca do Nascimento Miranda, em homenagem à educadora curitibana. Hoje, a denominação da escola é Colégio Estadual Dona Branca do Nascimento Miranda - Ensino Fundamental e Médio (SEED, [s/d] [s/p]).

\section{Considerações Finais}

As primeiras décadas do século $\mathrm{XX}$ foram de grandes transformações na cidade de Curitiba. Ao mesmo tempo em que mantinha uma paisagem de cidade pequena e até certo ponto provinciana, a capital do estado tentava se modernizar, se tornar civilizada e mais próxima dos modelos vindos da Europa. Nesse processo, os habitantes da cidade viveram situações contraditórias, advindas da realidade ainda ligada à origem colonial do país, juntamente com os esforços de modernização que traziam o "progresso" das novas tecnologias, do saneamento, da urbanização, das propostas higienistas, do consumo e da educação científica e laica.

Ser mulher na Curitiba da modernidade significava viver dentro desse contexto de transformações e ambiguidades. Ao mesmo tempo em que os mecanismos do sistema, marcado 
pela profunda desigualdade social, pelo racismo e pelo patriarcalismo eram a regra nas relações sociais, existia a possibilidade de novas tentativas de inserções de grupos marginalizados, que lutavam por direitos e visibilidade naquele contexto. Era um processo complexo, onde muitas rupturas haviam acontecido recentemente, como a emancipação política do Paraná (1853), abolição da escravidão (1888) e a mudança do regime imperial para o republicano (1889), fatos que trouxeram profundas alterações na estrutura econômica, social e cultural daquela sociedade. Concomitantemente com essas mudanças, as imposições para a manutenção das formas arcaicas de poder e dominação permaneciam como regra, inserindo-se aí as formas de opressão masculina diante das lutas feministas por emancipação e representatividade.

Importante também ressaltar que, ser mulher naquele contexto não remete a um grupo homogêneo caracterizado apenas por seu caráter identitário. As mulheres das classes populares viviam realidades bastante distintas daquelas pertencentes às classes mais abastadas. $\mathrm{O}$ acesso à segurança material, à educação e aos novos recursos que a modernização trazia, fazia com que as mulheres das elites pudessem vivenciar o processo de lutas pela visibilidade feminina de maneira diferenciada, devido a seu acúmulo de capitais econômicos, familiares, educacionais, profissionais e sociais.

Neste contexto, a história de Maria Branca Garcez do Nascimento Miranda se constitui num interessante estudo de caso. Advinda de famílias de classe média e da elite, a jovem Branca adquiriu uma formação escolar que não era a regra para a maioria das jovens brasileiras naquela época. Uma vez formada professora pela Escola Normal de Curitiba, exerceu o magistério até o seu casamento, mas se absteve do exercício de sua profissão posteriormente por diversos anos, devido às imposições do marido. Por meio de uma estratégia conciliadora, conseguiu retornar à atuação docente, ensinando em salas de aula dentro de sua própria residência. Os capitais que acumulou como membro de uma família abastada contribuiu para que Dona Branca pudesse estender a formação educacional para seus filhos homens e também para suas filhas mulheres. O próprio casamento com Guilherme Xavier de Miranda (industrial também oriundo de grupos bem estabelecidos na cidade), além de representar uma aliança familiar importante, propiciou novos acúmulos de capitais, que geraram significativos recursos para a manutenção dessa estirpe nos círculos influentes da sociedade curitibana. Sempre presente em eventos sociais relevantes da elite local, a família Xavier de Miranda se afirmou como parte dos grupos dominantes, e reproduziu seu habitus na preservação do status econômico, na perpetuação das 
Revista NEP - Núcleo de Estudos Paranaenses, Curitiba, v.5, n.1, jun. 2019

alianças familiares garantidas por meio dos casamentos, e na reprodução de muitos valores da dominação patriarcal.

Entretanto, mesmo que a lógica da reprodução do habitus e os mecanismos da dominação simbólica apontem para a preservação das estruturas de opressão (seja nas relações de classe ou de gênero), a participação das mulheres que pertenciam à elite tradicional curitibana no processo de transformações da modernidade (como é o caso de Branca do Nascimento Miranda) são exemplos de trajetórias que assinalam as mudanças sociais, culturais e pessoais da época, e são indícios das possíveis brechas existentes naquele sistema. Dentro dessa dinâmica, as lutas por visibilidade e direitos das pautas feministas foram travadas das mais diversas formas, por meio de embates mais contundentes e diretos (como o que foi feito por diversas intelectuais, escritoras ou educadoras da época), ou através de estratégias mais discretas e conciliadoras (como fez Dona Branca ao encontrar uma forma de permanecer lecionando).

Portanto, o fato é que as mulheres participaram das mais diversas maneiras do processo complexo de transformações do início do século XX e, apesar das contradições daquele contexto, não se furtaram a ocupar espaços, mesmo que na superfície, a dominação masculina ainda nos pareça completa, e o gênero da modernidade ainda aparente pertencer aos homens.

\section{Referências}

A REPÚBLICA, 11 de dezembro de 1902, p. 1. "Conservatório de Belas Artes". Disponível em:

$<$ http://memoria.bn.br/DocReader/DocReader.aspx?bib=215554\&pesq=Branca\%20do\%20Na scimento >. Acesso em: 15 fev. 2019.

A REPÚBLICA, 9 de dezembro de 1902, p. 2. “Conservatório de Belas Artes”. Disponível em: $<$ http://memoria.bn.br/DocReader/DocReader.aspx? bib=215554\&pesq=Branca\%20do\%20Na scimento>. Acesso em: 15 fev. 2019.

A REPÚBLICA, 19 de novembro de 1903, p. 1. "Diversas". Disponível em: $<$ http://memoria.bn.br/DocReader/DocReader.aspx?bib=215554\&PagFis=15050\&Pesq=mari a\%20branca\%20nascimento >. Acesso em: 11 fev. 2109.

A REPÚBLICA, 3 de março de 1904, p. 2. "Exames de admissão". Disponível em $<$ http://memoria.bn.br/DocReader/DocReader.aspx ?bib=215554\&pesq=Branca\%20do\%20Na scimento >. Acesso em: 19 fev. 2019. 
A REPÚBLICA. 02 de dezembro de 1909, p. 2. "Pelas Escolas". Disponível em. $<$ http://memoria.bn.br/DocReader/DocReader.aspx ?bib=215554\&PagFis=15391\&Pesq=Bran ca\%20do\%20Nascimento>. Acesso: 13 fev. 2019.

A REPÚBLICA, 5 de dezembro de 1917, p. 8. "Seção Livre - Novenas do S. Bom Jesus". Disponível em: $<$ http://memoria.bn.br/DocReader/DocReader.aspx ?bib=215554\&pesq=branca\%20do\%20nas cimento\%20miranda>. Acesso em: 29 jan. 2019.

ARAÚJO, S.A.C. "Professora Julia Wanderley, um mito na feminização do magistério paranaense (1874-1918)", [s/d]. $<$ http://sbhe.org.br/novo/congressos/cbhe7/pdf/05-

\%20HISTORIA\%20DA\%20PROFISSAO\%20DOCENTE/PROFESSORRA\%20JULIA\%20 WANDERLEY.pdf>. Acesso em: 18 fev. 2019.

BOURDIEU, P. A dominação masculina. Rio de Janeiro: Bertrand Brasil, 2012.

CASTRO, E. A. A arquitetura das escolas públicas do Paraná (1853-1955). Curitiba: [s/ed], 2018.

COLÉGIO ESTADUAL DONA BRANCA DE NASCIMENTO MIRANDA. "Biografia". Curitiba: [s/ed], [s/d].

CORREIO DO PARANÁ, 31 de dezembro de 1932, p. 1. "Nomeado governador do território do Iguaçu". Disponível em: <http://memoria.bn.br/DocReader/DocReader.aspx?bib=171395\&pesq=Jo\%C3\%A3o\%20Gar cez\%20do\%20Nascimento $>$. Acesso em: 18 fev. 2019.

CORREIO DO PARANÁ, 16 de julho de 1937, p. 9. "Notas Sociais". Disponível em: <http://memoria.bn.br/DocReader/DocReader.aspx?bib=171395\&pesq=branca\%20do\%20nas cimento\%20miranda>. Acesso em: 29 jan. 2019.

CUNHA, R. T. F. A feminização da cultura: Curitiba, 1890 - 1930. Dissertação de mestrado. Universidade Estadual de Campinas (UNICAMP). Instituto de Filosofia e Ciências Humanas (IFCH), 2001.

DIÁRIO DO PARANÁ, 31 de março de 1957, p. 3. "Nossa sociedade". Disponível em $<$ http://memoria.bn.br/DocReader/DocReader.aspx?bib=761672\&pesq=branca\%20do\%20nas cimento\%20miranda>. Acesso: 10 fev. 2019.

DIÁRIO DO PARANÁ, 12 de julho de 1962, p. 1. "Enquadrados 135 dentista no quadro geral". Disponível em: <http://memoria.bn.br/DocReader/DocReader.aspx?bib=761672\&pesq=Maria\%20Anuncia\% C3\%A7\%C3\%A3o\%20de\%20Miranda>. Acesso em: 16 fev. 2019.

FELSKI, R. The Gender of Modernity. Cambridge: Harvard University Press, 1995. 
Revista NEP - Núcleo de Estudos Paranaenses, Curitiba, v.5, n.1, jun. 2019

FOGGIATO, F. "Mariana Coelho: precursora na luta pelos direitos da mulher", 2017. Disponível em: 〈https://www.cmc.pr.gov.br/ass_det.php?not=27523\#\&panel1-1 >. Acesso em: 18 fev. 2019.

GOVERNO DO ESTADO DO PARANÁ. "Casa civil - Caetano Munhoz da Rocha”, [s/d]. Disponível em: $\langle$ http://www.casacivil.pr.gov.br/modules/conteudo/conteudo.php?conteudo=60 $>$. Acesso em: 15 fev. 2019.

ILLOUZ, E. El consumo de la utopía romántica. El amor y las contradicciones culturales del capitalismo. Madrid-Buenos Aires: Katz, 2009.

INSTITUTO DE EDUCAÇÃO DO PARANÀ - IEP. "Histórico do Instituto de Educação do Paraná Professor Erasmo Pilotto", [s/d]. Disponível em: <http://institutoerasmopilotto.blogspot.com/p/historico.html $>$. Acesso em: 12 fev. 2019.

MENDONÇA, J. M. N.; SOUZA, J. U. (org). Paraná insurgente: histórias de lutas sociais séculos XVIII ao XXI. São Leopoldo: Casa Leiria, 2018.

NEGRÃO, F. Genealogia paranaense. Volume $3^{\circ}$. Curytiba: Impr. Paranaense, 1928.

O COMMERCIO, 21 de janeiro de 1909, p. 2. "Cynematographos". Disponível em <http://memoria.bn.br/DocReader/DocReader.aspx? bib=304948\&pesq=Branca\%20do\%20Na scimento> Acesso: 16 fev. 2019.

O DIA, 8 de setembro de 1936, p. 1. "Iniciando o movimento pró erecção da Igreja de Sta. Therezinha". Disponível em: < http://memoria.bn.br/DocReader/DocReader.aspx? bib=092932\&PagFis=32277\&Pesq=branc a\%20do\%20nascimento\%20miranda $>$. Acesso em: 29 jan. 2019.

O DIA, 24 de abril de 1941, p. 7. "Primeira Seção". Disponível em: <http://memoria.bn.br/DocReader/DocReader.aspx ?bib=092932\&PagFis=34802\&Pesq=branc a\%20do\%20nascimento\%20miranda>. Acesso em: 20 jan. 2019.

O DIA, 4 de janeiro de 1944, p. [s/p]. "Nomeado governador do território do Iguaçu". Disponível em: $<$ http://memoria.bn.br/DocReader/DocReader.aspx?bib=092932\&pesq=Jo\%C3\%A30\%20Gar cez\%20do\%20Nascimento>. Acesso em: 18 fev. 2019.

O DIA, 02 de dezembro de 1944, p. 2. "Cincoentenário do grêmio das violetas". Disponível em:

$<$ http://memoria.bn.br/DocReader/DocReader.aspx ?bib=092932\&pesq=Branca\%20do\%20Na scimento>. Acesso em: 15 fev. 2019.

OLIVEIRA, J. M. Tradução de 'FELSKI, R. The Gender of Modernity. Cambridge: Harvard University Press, 1995. Curitiba: [s/ed], 2019. 
Revista NEP - Núcleo de Estudos Paranaenses, Curitiba, v.5, n.1, jun. 2019

PERES, A. "Lista de falecimentos", 2010. Disponível em: <https://www.gazetadopovo.com.br/servicos/falecimentos/lista-de-falecimentos08bakqlkcq4k74nv2z6jar77y/>. Acesso em: 30jan. 2019.

PERROT, M. Minha história das mulheres. São Paulo: Contexto, 2007.

PUPPO, J. "O Gênero da Modernidade Rita Felski - Tradução - Introdução - Mitos do Moderno", 2013. Disponível em <https://pt.scribd.com/document/150967457/O-Genero-daModernidade-Rita-Felski-Traducao-Introducao-Mitos-do-Moderno-Joana-Pupo.> Acesso: $15 / 02 / 2019$.

SECRETARIA DE EDUCAÇÃO DO ESTADO DO PARANÁ - SEED. "Colégio Estadual Dona Branca do N. Miranda", [s/d]. Disponível em: $<$ http://www.ctabrancamiranda.seed.pr.gov.br/modules/conteudo/conteudo.php? conteudo=14 $\geq$ Acesso: $15 / 02 / 2019$.

TRINDADE, E M C. Clotildes ou Marias: mulheres de Curitiba na $1^{\text {a }}$ República. Curitiba: Fundação Cultural, 1996.

VIANA, I. "Magistério Público no Paraná: feminização e representação sobre a carreira (18571930)". X Congresso Nacional de Educação - EDUCERE. I Seminário Internacional de Representações Sociais, Subjetividade e Educação - SIRSSE. Pontifícia Universidade Católica do Paraná. Curitiba, 2011, p. 2300-2314. 
Revista NEP - Núcleo de Estudos Paranaenses, Curitiba, v.5, n.1, jun. 2019

\section{Anexo 1}

\begin{tabular}{|c|c|}
\hline Nome & $\begin{array}{l}\text { Maria Branca Garcez do Nascimento Miranda (1892-1954). } \\
\text { (COLÉGIO ESTADUAL DONA BRANCA DE NASCIMENTO MIRANDA, [s/d]) }\end{array}$ \\
\hline $\begin{array}{l}\text { Filiação/ } \\
\text { parentescos/ } \\
\text { capitais } \\
\text { familiares }\end{array}$ & $\begin{array}{l}\text { Pai: Francisco Gonçalves Nascimento Rosa (? 1915) - militar, chefe de fiscalização e arrecadação das } \\
\text { rendas do Barracão, hoje Dionísio Cerqueira - PR. } \\
\text { Mãe: Olympia Garcez do Nascimento (?.- 1923) - filha de João Moreira Garcez (não se trata do prefeito } \\
\text { de Curitiba nas décadas de } 1920 \text { e 1930) e Marianna Theodora Ferreira Garcez. } \\
\text { Irmã: Maria Rosa do Nascimento Bittencourt - Professora formada na Escola Normal de Curitiba. } \\
\text { Casada com Dr. Theodorico Camargo Bittencourt. } \\
\text { Irmã: Elfrida Garcez do Nascimento - viúva do Major Dr: Theophilo Garcez Duarte, Engenheiro } \\
\text { militar. } \\
\text { Irmão: Dr. Euripedes Garcez do Nascimento, - Dr. Loth -, médico formado pela Academia de Medicina } \\
\text { da Universidade Federal do Paraná. Casado com_ Maria Antonietta Lopes. } \\
\text { Irmão: João Garcez do Nascimento. Coronel do Exército, foi ajudante de ordens da Presidência da } \\
\text { República durante o governo de Getúlio Vargas na década de 1930, e em 1944 foi nomeado por Vargas } \\
\text { como governador do Território do Iguaçu no Paraná (NEGRÃO, 1928) (CORREIO DO PARANÁ, } 31 \text { de } \\
\text { dezembro de 1932, p. 1) (O DIA, } 4 \text { de janeiro de 1944, p. [s/p]). }\end{array}$ \\
\hline $\begin{array}{l}\text { Casamento/ } \\
\text { capitais } \\
\text { familiares }\end{array}$ & $\begin{array}{l}1912 \text { - Contraiu núpcias com o industrial Guilherme Xavier de Miranda Junior, filho do industrial da } \\
\text { erva mate, ex- vereador e ex-prefeito da cidade de Curitiba, Guilherme Xavier de Miranda. Também } \\
\text { seguiu a carreira de industrial (NEGRÃO, 1928). }\end{array}$ \\
\hline $\begin{array}{l}\text { Capitais } \\
\text { educacionais }\end{array}$ & $\begin{array}{l}\text { 1902 - instrução primária no Conservatório de Belas Artes de Curitiba. } \\
\text { - Presença de Octávio Ferreira do Amaral (Secretário do Interior) e Sebastião Paraná (Inspetor escolar, } \\
\text { jornalista e deputado) em sua banca examinadora. } \\
\mathbf{1 9 0 3} \text { - instrução primária na turma da Professora Maria Rosa do Nascimento Bittencourt em Curitiba. } \\
\mathbf{1 9 0 4 - 1 9 0 5} \text { - instrução primária na Escola Oliveira Bello em Curitiba. } \\
\mathbf{1 9 0 6 - 1 9 0 9} \text { - formação para o magistério na Escola Normal de Curitiba. } \\
\text { (A REPÚBLICA, } 19 \text { de novembro de } 1903, \text { p. 1.) (A REPÚBLICA. } 02 \text { de dezembro de } 1909, \text { p. } 2 \text { ) } \\
\text { (CORREIO DO PARANÁ, } 31 \text { de dezembro de 1932, p. 1) (CORREIO DO PARANÁ, } 16 \text { de julho de } \\
\text { 1937, p. 9) (O DIA, } 4 \text { de janeiro de } 1944, \text { p. [s/p]). }\end{array}$ \\
\hline $\begin{array}{l}\text { Capitais } \\
\text { profissionais }\end{array}$ & $\begin{array}{l}1909 \text { - Examinadora na banca de avaliações do Colégio Americano em Curitiba. } \\
1928 \text { - } 1952 \text { - Professora ministrante de aulas para formação primária particular em sua residência (A } \\
\text { REPÚBLICA, } 19 \text { de novembro de 1903, p. 1.) (A REPÚBLICA. 02 de dezembro de 1909, p. 2) } \\
\text { (CORREIO DO PARANÁ, } 31 \text { de dezembro de 1932, p. 1) (CORREIO DO PARANÁ, 16 de julho de } \\
\text { 1937, p. 9) (O DIA, } 4 \text { de janeiro de 1944, p. [s/p]) (COLÉGIO ESTADUAL DONA BRANCA DE } \\
\text { NASCIMENTO MIRANDA, [s/d]). }\end{array}$ \\
\hline $\begin{array}{l}\text { Capitais } \\
\text { Sociais }\end{array}$ & $\begin{array}{l}\text { - Participação em festas e eventos católicos em Curitiba. } \\
\text { - Participação do Grêmio das Violetas, agremiação pertencente ao Clube Curitibano (A REPÚBLICA, } 19 \\
\text { de novembro de 1903, p. 1.) (A REPÚBLICA. 02 de dezembro de 1909, p. 2) (CORREIO DO } \\
\text { PARANÁ, } 31 \text { de dezembro de 1932, p. 1) (CORREIO DO PARANÁ, } 16 \text { de julho de 1937, p. 9) (O DIA, } \\
4 \text { de janeiro de 1944, p. [s/p]). }\end{array}$ \\
\hline
\end{tabular}


Revista NEP - Núcleo de Estudos Paranaenses, Curitiba, v.5, n.1, jun. 2019

\section{Anexo 2}

Biografia exposta em texto enquadrado no Colégio Estadual Dona Branca do Nascimento Miranda em Curitiba.

Biografia

Dona Branca do Nascimento Miranda

Nascida em Curitiba, em 16 de julho de 1892.

Filha de Francisco do Nascimento Miranda e Rosa Olimpia Garcez do Nascimento.

Iniciou suas primeiras letras com sua irmã, prosseguiu seus estudos na escola particular da Professora Mariana Coelho.

Desde cedo mostrou sua inclinação para o Magistério. Ingressou na Escola Normal que na época funcionava no Ginásio Paranaense, com muito entusiasmo, dedicação e amor ao estudo. Sempre se salientou no curso.

Foi aluna de grandes mestres da época, como David Veloso, Lisímaco da Costa, Emílio de Menezes e tantos outros que sempre a distinguiram com elogios. Ainda estudante, já auxiliava sua irmã professora primária, substituindo-a quando necessário.

Casou-se em 1912 com Guilherme Xavier de Miranda.

Pelo ano de 1928, iniciou sua vida profissional, lecionando para alguns sobrinhos. Logo a notícia se espalhou e começaram os pedidos que aceitasse mais alunos.

Assim, pela energia e capacidade, rapidamente conseguiu tornar-se conhecida.

Muitos de seus alunos foram preparados para o Colégio Militar do Rio de Janeiro.

No governo do Dr. Caetano Munhoz da Rocha, diversas vezes foi convidada pelo Dr.

Lysímaco Ferreira da Costa, então Secretário da Educação, para assumir a Direção da Escola

Normal. Mas, como deveria afastá-la do lar e de sua Escola, recusou o convite.

Durant e 25 anos de sua vida, devotados ao Magistério, dedicou especial atenção ao ensino e educação de seus alunos, que em todas as ocasiões recordam com saudade, lembrando até hoje de seus ensinamentos.

Faleceu em 27 de dezembro de 1954.

(COLÉGIO ESTADUAL DONA BRANCA DE NASCIMENTO MIRANDA, [s/d]).

Recebido em: 30 maio 2019.

Aceito em: 10 jun. 2019. 